measures, as well as useless treatment with toxic entities such as amphotericin $B$, which would have been used in these cases. Although $F$ verticillioides was identified as a contaminant in this episode, it cannot always be assured to be the consequence of laboratory contamination. For this reason, it is of fundamental importance to conduct a careful examination both of the patient's clinical records and of the work protocol in other wards and in the laboratory, so that the results of the cultures may be critically interpreted in a clinical way. It also seems opportune to identify the microorganism at the species level and, in case of outbreak, to use a molecular typing method to establish a link with an environmental source.

Only close, constructive, and timely collaboration between the microbiology laboratory and the diagnostic and nursing wards can permit prompt identification of such episodes and establish the common denominator that unites patients who are quite different but are linked by the isolation of an often unusual microorganism. Furthermore, close collaboration with the hospital pharmacy is needed to establish suitable containment measures for such an episode, adopting precautionary measures (such as withdrawing the contaminated equipment) and proposing administrative tasks (such as notifying the suppliers and the Ministry of Health) in order to bring about systematic quality control of commercial sterile products. ${ }^{9}$

From the Microbiology and Virology Institute (Drs. Grigis, Farina, and Goglio), Azienda Ospedaliera 'Ospedali Riuniti di Bergamo,'
Bergamo, Italy, and the Scientific Institute of Public Health Louis Pasteur' (Drs. Symoens and Nolard), Brussels, Belgium.

Address reprint requests to Claudio Farina, MD, Microbiology and Virology Institute, Azienda Ospedaliera 'Ospedali Riuniti di Bergamo,' largo Barozzi 1-24128 Bergamo, Italy.

98-OA-201. Grigis A, Farina C, Symoens F, Nolard N, Goglio A. Nosocomial pseudo-outbreak of Fusarium verticillioides associated with sterile plastic containers. Infect Control Hosp Epidemiol 2000;21:50-52.

\section{REFERENCES}

1. Kusek JW. Nosocomial pseudoepidemics and pseudoinfections: an increasing problem. Am J Infect Control 1981;9:70-75.

2. Van Vaerenbergh B, Grootaert B, Moens W. Validation of a method for preparation of fungal genomic DNA for polymerase chain reaction (PCR) and random amplification of polymorphic DNA (RAPD). J Mycol Méd 1995;5:133-139.

3. Orr KE, Holliday MG, Gould FK. Pseudobacteremia caused by contaminated commercial blood culture broths. J Infect 1994;28:109-110.

4. Berkelman RL, Lewin S, Allen JR, Anderson RL, Budnick LD, Shapiro S, et al. Pseudobacteremia attributed to contamination of povidone-iodine with Pseudomonas cepacia. Ann Intern Med 1981;95:32-36.

5. Astagneau P, Gottot S, Gobin Y, Bocquet P, Gatignol C, Jouvet P, et al. Nosocomial outbreak of Enterobacter agglomerans pseudobacteremia associated with non-sterile blood collection tubes. $J$ Hosp Infect 1994;27:73-75.

6. Rathbone PG, Sinickas V, Humphery V, Graves S, Hellyar A. Polymicrobial pseudobacteremias associated with non-sterile sodium citrate blood collection tube. I Hosp Infect 1993;25:297-299.

7. Griffin MR, Miller AD, Davis AC. Blood culture cross contamination associated with a radiometric analyzer. J Clin Microbiol 1982;15:567-570.

8. Schar G, Grehn M, von Graeventiz A. Persistent colonization of carbon dioxide incubators with Candida parapsilosis. Eur J Clin Microbiol Infect Dis 1990:9:758-760.

9. Crawford SY, Narducci WA, Augustine SC. National survey of quality assurance activities for pharmacy-prepared sterile products in hospitals. Am J Hosp Pharm 1991;48:2398-2413.

\title{
Molecular Epidemiology of VRE in New York
}

\section{Gina Pugliese, RN, MS Martin S. Favero, PhD}

Bopp and colleagues determined the distribution of vancomycinresistant enterococci (VRE) within and between six New York State hospitals, using antibiotic susceptibility testing, pulsed-field gel electrophoresis (PFGE) fingerprinting, plasmid profile analysis, van $\mathrm{A}$ and van $\mathrm{B} \mathrm{PCR}$, and DNA: DNA hybridization with van $\mathrm{A}$ and $\operatorname{van} \mathrm{B}$ probes.

PFGE and plasmid typing generally agreed, but plasmid profiles were more variable. Genetic heterogeneity among isolates from within each of the six hospitals varied considerably.
Among 23 Enterococcus faecium isolates from one hospital, there were only 3 PFGE types, and 20 isolates had the same type. However, in another hospital, each isolate was genetically distinct. Closely related strains were not found in separate hospitals. VRE strains with vanA genes and strains with $\operatorname{van} \mathrm{B}$ genes were found in three hospitals. Both plasmid and chromosomal carriage of these genes was detected. PFGE typing showed that nosocomial VRE transmission had occurred in some hospitals. However, there was no evidence for it in others; neither was there evidence for intrahospital transmission or for emergence of an endemic strain.
These observations demonstrate that it is important to evaluate genetic heterogeneity among VRE before implementation of infection control measures. PFGE is the method of choice for epidemiological typing, but PCR, plasmid, and hybridization studies can provide important information concerning the presence and potential for transfer of vancomycin resistance genes.

FROM: Bopp LH, Schoonmaker DJ, Baltch AL, Smith RP, Ritz WJ. Molecular epidemiology of vancomycin-resistant enterococci from 6 hospitals in New York state. $A m J$ Infect Control 1999;27:411-417. 